\title{
Exploring the coaction of motivation and learning styles in educational gamification: A preliminary study for understanding 'motivational learning modes'
}

\author{
Joana Pereira \\ Leeds University Business School \\ j.pereira@leeds.ac.uk
}

\author{
Josh Morton \\ Leeds University Business School \\ j.morton1@leeds.ac.uk
}

\author{
Lina Gomes \\ Mindflow \\ Lina.gomes@mindflow.pt
}

\begin{abstract}
This study explores the different motivations and learning styles of students using a game for revision in a leading university. The research is unique in attempted to understand the coaction of motivation and learning style through rich qualitative empirical work, which unpacks the opinion of game users and their inherent real-life experience of educational gamification and associated game elements. Our findings indicate that there are three specific modes of interaction between motivation and learning which we call 'motivational learning modes'. As this is a preliminary study, we conclude by detailing our future work and fruitful avenues for expanding educational gamification research based on our insights.
\end{abstract}

\section{Introduction}

Research on gamification has increased substantially in recent years and is concerned with "using game-based mechanics, aesthetics and game thinking to engage people, motivate action, promote learning, and solve problems" ([14]). The pedagogical application of gamification has been heavily pursued by institutions - from junior and high schools to colleges and universities as a way of potentially increasing student engagement in learning and promoting new modes of interaction in the classroom. It has emphasized that matching learning styles of students with an appropriate form of instructional intervention impacts on learning ability and performance ([3]). Essentially, different mechanisms used in educational gamification will be utilized in a variety of ways by students based on their own learning styles. The connection of such learning styles with extant motivation has also been suggested as an interesting dynamic, in which the two combine to have an impact - both positive and negative - on learning through gamification in educational settings ([26]; [3]).

This preliminary research responds to this emerging area of interest in educational gamification and identifies the dynamic of motivation and learning styles as specific 'modes of interaction'. We label these modes 'motivational learning' to recognize the coaction between motivation and preferences in style of learning. These modes are learners (demonstrating a mode through which students enjoy gamification for learning core information related to the course topics), gamers (demonstrating a mode through which students enjoy game elements such as badges, high scoring on leaderboards and dueling other players), and finally hybrids (demonstrating a mode through which students enjoy elements of the two and balance these in their experience of gamification). This study is also unique in understanding motivation and learning styles from a qualitative perspective, with gathering of rich student opinion and evaluation of game use at the forefront of the empirical work. The following research question is posed:

"How does the coaction of motivation and learning styles in educational gamification represent specific modes of interaction?".

The paper represents an initial preliminary study of a sample, as part of an on-going project exploring gamification in education at a world top 100 university. The paper is structured as follows; first, we review extant literature, focusing in particular on the origins of gamification and educational gamification, design elements and motivation theory, and an exploration of motivation and learning styles. Second, we offer an overview of the research methodology and detail our theoretical lens. Third, we explicate the empirical context, a game used for learning on a university Strategic Management module. Fourth, the analysis and findings are presented, and the main 
contribution is derived, a framework which shows modes of interaction in educational gamification. Lastly, we discuss the findings in relation to prior literature and theory and offer implications for research and practice before concluding with reflection on our study and avenues for future research.

\section{Literature review}

The literature on gamification to date is emerging, but remains dispersed across some different disciplines, such as human-computer interaction, pedagogy, information systems, and psychology. In this literature review we do not intend to offer an extensive review of all of these extent works, but instead focus briefly on the origins of gamification and gamification in learning, anfd then more substantially on gaming features and design; to connect with our empirical context, and on psychological aspects relating to gamification; to link to our focus on motivation and learning styles.

\subsection{Origins of gamification and educational gamification}

The use of games and game design elements in educational settings is becoming more prominent. However, while advances in information technology (IT) and networked environments have enhanced games and made them more accessible, gamification is not 'new'. Indeed, it can be traced back to the 1960s ([25]) when it was emphasized that games could be useful in not only help children to excel in their learning environment, but also in enhancing their imagination about distinct topics and themes in education. Following this were a number of pioneering works that started to emphasize new ways of thinking about games not just as entertainment, but as mechanisms for knowledge sharing, acquisition and learning ([1]; [20]; [19]; [18]).

In more recent research, there has been a principal focus on understanding the rich uses of gamification in human-computer interaction, such as the exploration of 'serious-games' and game-based learning theories and outcomes, and intrinsic and extrinsic motivations in gamification use ([7]). Further, information systems scholars have been interested in game design elements, and the interaction between material and social actors in utilizing different features, which afford action in game-based interaction and learning ([16]; [11]; [17]). We explore more on design elements, motivation theory and learning theories throughout this review.

\subsection{Design elements in educational gamification and motivation theory}

This section of the literature review explores different game design elements and their relation to motivation theory; specifically 'self-determination theory' and its core concepts relating to educational gamification. One of the most important aspects of gamification and game design is the motivation that impels users to play ([7]). For example, 'freedom of choice' is a strong driver of motivation, and intrinsically motivated behaviors are those whose motives are based on the satisfaction of behavior itself rather than on operationally separate reinforcements of those activities ([5]). Further, self-determination theory emphasizes four 'mini-theories' which suggest the need for competence and autonomy is central to motivation in playing games, particularly in intrinsic motivation ([6]; [5]).

In educational gamification, the game elements are determinant to foster motivation and engagement towards the game, what in turn will improve players' learning curves. It has been suggested that there are a number of ingredients for great games ([27]), these being; self-representation with avatars, threedimensional environments, narrative context, feedback, reputations, ranks and levels, marketplaces and economies, competition under rules that are explicit and enforced, teams, parallel communication systems that can be easily configured, and time pressure. Games often combine these ingredients in different ways, and indeed some of these elements are deemed more suitable to online and digital games, and others to more traditional 'analogue' games such as table-top puzzles, and board games. The use and suitability of different game elements find their foundation in the rich psychology literature, specifically on motivation and self-determination theories. In the context of educational games, such elements leverage players engagement regarding the time they play, and the impact gaming has on their learning process.

To build on these elements or 'ingredients' and their impact on engagement and motivation, one example is the option for users to choose an avatar that represent the player and promotes autonomy and selfdetermination. Other gamification elements such as rankings have been found to enhance motivation ([21]), whilst features such as levels can promote the sense of competence related to intrinsic motivation 
([5]). Games often use the difficulty of levels, which increase over time, and the random presentation of questions, as ways of guaranteeing a high probability of repetition and ensuring users learn by trial-and-error whilst consolidating their learning in repetition. This is another design element which can enhance motivation through developing a sense of competence for users, by having immediate feedback on their growing performance ([2]).

The use of badges as a design element in gamification has been a more prominent development in the last decade (and has also been driven by its use in high-profile console game development such as 'achievements' on Xbox and 'trophies' on PlayStation) ([14]). Badges encourage play behavior as a mechanism to achieve 'something', and therefore reinforce players behavior such as playing in the morning or night, or in a certain style (faster answering, number of hours played, accuracy of answering). The use of this element aims to reinforce certain behavior, stimulate persistence, and ultimately drive different motivation for continued use of games, even in situations in which the user does not have significant notoriety in rank.

Although it has been suggested that positive reinforcement, such as motivation driven by badges and set achievements, plays an important role in learning by behavioral conditioning, it has also been expressed that "while reward-based gamification can be useful for short-term goals and situations where the participants have no personal connections or intrinsic motivation to engage in a context, rewards can reduce intrinsic motivation and the long-term desire to engage with the real world context" ([24]). Therefore, rewards attributed by badges might only promote short-term behavior and motivation in the gaming. Long-term learning, however, will instead be related to the intrinsic motivation nurtured by the development of the sense of competence, again a central concept evidenced self-determination theory ([5]). For example, users can gain motivation through feeling a degree of 'knowledge gain' when working through questions or levels as a means of progressive performance or being progressively faster as competence builds over time.

A final theme to be explored is cooperation in selfdetermination theory, and extant research has indicated that cooperation is considerably more effective than interpersonal competition and individualistic efforts in game contexts ([13]). For example, gamification elements, such as individual challenges and battles amongst teams of players enhances both competitive and cooperative strategies in order to leverage intrinsic and extrinsic motivation. Together, these design elements can also stimulate a sense of collective motivation and being with groups of users. It can, therefore, be said that selfdetermination theory is the basis of design elements in relation to motivation, particularly in educational gamification and also the case explored in the empirical work in this paper.

Although behaviorism suggests that positive reinforcement plays an important role in learning, particularly through the notion of behavioral conditioning, Nicholson ([24]) suggests that "while reward-based gamification can be useful for shortterm goals and situations where the participants have no personal connections or intrinsic motivation to engage in a context, rewards can reduce intrinsic motivation and the long-term desire to engage with the real world context". This demonstrates some contradiction and uncertainty in relation to rewards and their role in motivation for gamers.

\subsection{Educational gamification and learning theories: motivation and learning styles}

This section of the literature review builds on the evaluation of design elements and motivation theory, to explore learning theories. Specifically, the focus here is on motivation and learning styles. Learning styles are unique to different people, and in educational gamification users also have unique motivation to their learning process ([3]). Learning styles are defined as the manner in which people approach learning tasks through their unique characteristics ([12]). To emphasize the vast degree of learning styles, one review identified 71 different learning style models ([4]), and it is an area that remains convoluted and diverse of opinion.

There are a few particularly prominent frameworks which have been seminal in understanding learning styles, including in educational settings. For example, the Learning Style Inventory (LSI) identified four stages in an iterative model to describe how learning occurs over time ([15]). The Index of Learning Styles (ILS) is prominent and particularly relevant in relation to educational gamification as it helps to understand the distinct learning styles of students ([9]; [3]). The primary objective of the ILS is to "provide guidance to instructors on the diversity of learning styles within their classes and to help them design instruction that addresses the learning needs of all their students" ([10]). It has been noted more recently that the four dimensions of the ILS are representative of various 
other learning style models ([10]) and thus represents as close as we have at present in research to an allencompassing model to represent learning styles. For example, the ILS built on Kolb's ([15]) work in identifying and refining that learning styles can be categorized to individuals along four dimensions, and these are discussed briefly here.

The first dimension is 'sensing-intuitive' $(\mathrm{S} / \mathrm{I})$ and relates to how a student perceives the world ([23]; [3]). Students who align with sensing like learning facts and solving problems using well-established methods, and do not favor surprises in their learning process. Instead, they are patient with details, good at memorizing and like making notes and other 'handson' approaches. Intuitive learners prefer discovering possibilities and the relationships between concepts and are innovative and dislike repetition and routine learning.

The second dimension is 'visual-verbal' (V/V) and relates to how information is most effectively perceived by learners. This dimension, in particular, differentiates students who are visually orientated from students who are verbally orientated. Visual learners prefer visual information transmission methods such as pictures, diagrams, flow charts and time lines, while verbal learners prefer written and spoken explanations ([3]).

The third dimension is 'active-reflective' (A/R) and relates to the processing of information. Active learners prefer to learn by engaging in activities related to the learning process. An example might be discussions with colleagues or classmates, or a physical learning activity. They tend to enjoy group interaction. Reflective learners prefer to think about new information and concepts quietly using introspective processes. They prefer to work independently and to their own guidelines and routine ([3]).

Finally, the fourth dimension is 'sequential-global' (S/G) and emphasizes that learners may be classified along a dimension characterized by sequential and global learners. More specifically, sequential learners prefer to progress towards understanding in logical, sequential steps, with each step following from the previous one. It follows a pattern of sorts and is 'predictable'. Global learners, in contrast, prefer to develop a broad overview of different areas of a topic, before then delving deeper in developing a more finetuned grasp of it. They may absorb material without necessarily seeing connections and then suddenly 'get it' and are more likely to solve complex problems quickly or put things together in innovative ways once they have grasped the 'big picture' view but may have difficulty explaining how they did it ([3]).

In sum, this framework is useful as a means to test learning styles, or alternatively can be used as a guide to understand learning in a more interpretive way.

\section{Methodology}

In this study, we collect data from two different sources, game performance data from the game used as the main focus of our study; 'Think strategically', and interviews with a sample of students who used the game for learning on a postgraduate Strategic Management module in a world top 100 university.

Game performance data encompasses a number of different factors, all of which were useful in developing a rich picture of how different students used the game and utilized key features. The factors include:

- ranking position

- time played

- level achieved in the game

- points

- badges won

- $\quad$ questions answered (both right and wrong)

- precision ratio

- battles played

- duels played

- rounds played

In total, we conducted 10 interviews with students that played the game. Again, this represents a preliminary study and sample before the game is further implemented into Strategic Management modules at the University, and potentially in further institutions, over the next two years where further data will be collected.

Overall, the students selected in this sample for the preliminary study represent different performance levels in terms of ranking position in the game (i.e. some scored very highly and positioned near the top of the leader board, some were in the middle, whilst some scored low) (see Table 1). This is useful when studying motivation and learning styles in gamified learning as it guides understanding of the different responses towards the game. 


\begin{tabular}{cccc}
\hline \multirow{2}{*}{$\begin{array}{c}\text { Interviewee } \\
\text { code }\end{array}$} & \multicolumn{3}{c}{ Game performance } \\
\cline { 2 - 4 } & Ranking & $\begin{array}{c}\text { Time } \\
\text { (hours) }\end{array}$ & Level \\
\hline HP & 1 & 4.0 & 30 \\
TH & 3 & 2.6 & 30 \\
SK & 4 & 3.2 & 30 \\
LM & 5 & 1.5 & 30 \\
OF & 7 & 1.2 & 30 \\
SS & 18 & 0.2 & 9 \\
SC & 20 & 0.7 & 9 \\
LP & 22 & 0.6 & 7 \\
JA & 26 & 0.5 & 5 \\
SY & 49 & 0.0 & 1 \\
\hline
\end{tabular}

TABLE 1. Interviewees' characteristics

We recorded and transcribed the interviews, which lasted on average 35 minutes. The interview protocol followed a semi-fixed structure with open-ended and follow-up questions ([28]). The interview protocol covered the following topics, which offered a solid basis towards an overview and balance of student motivation and different learning styles present in their use of the game:

- academic/professional background

- student learning mode

- learning experience with the game

- engagement/motivation towards the game

- barriers and enhancers

The data coding encompasses three stages. In the first stage, we executed rounds of descriptive crosscase coding ([22]). Two authors were involved in the coding to ensure validity of codes and rigor. Throughout this phase, first coding dimensions emerged from a data-literature interaction ([22]; [28]). A number of principle categories emerged and were organized by the focus on type of user in gamified learning and respective learning styles, to begin forming an understanding of modes of interaction in educational gaming (the 'learning traits'). Two authors coded a subset of the information independently, and after several rounds of interaction, they agreed on coding guidelines. In the second stage, the data analysis encompassed a within-case analysis, where the players profiles (in relation to motivation and learning styles) were developed. In a third phase, an in-depth comparative analysis was utilized, where we compared the patterns identified in the cases to analyze variations and similarities ([8]).

\section{Context: the 'Think Strategically' educational game}

This section of the paper offers a comprehensive overview of the empirical context, the 'Think Strategically' educational game. The game was utilized specifically for a module on Strategic Management within the case university. The game was devised principally for student revision, and students had three weeks to use the game before their formal examination.

The game uses a number of game elements, following the 'ingredients for great games' ([27]) and some of these were central to the game, whereas others were optional and could be used selectively (such as duels and battles). The following paragraphs summarize the features present in the "Think Strategically" educational game:

Self-representation with avatars: each user can choose a figure whose characterization will indicate the gender (female or male), age, and other elements such as beard, hair color, and use of glasses. The choice for an avatar promotes autonomy and 'freedom of choice', important instrinsic motivation drivers.

Competition under rules that are explicit and enforced: The rules are revealed to the user through the immediate and constant feedback they receive. In the home screen, there is the '?' button, which presents five questions and answers, summarizing the rules of the game. This information is complemented with a short video, where the user can receive an overview of how to operate the application and its features. When granting access to the game, the user is also informed of the key rules, namely the duration of the game and the criteria which define the 'winner'.

Ranking and Reputation: There are two rankings; the individual and the teams. In both of these rankings, the name (of the individual or the team) is displayed next to the number of points reached. The rank has a prominent place in the main menu so that users can easily consult it and are easily aware of its existence. The ranking is the most important element to boost individual and team reputation as all players can access the ranking and check each other's points and corresponding ranking position. The team ranking feature is important in not only boosting team reputation but also cooperation, another important element to promote both extrinsic and intrinsic motivation. 
Feedback: as players answer questions, they receive immediate feedback. When players answer a question correctly, for example, they see the color green, and when they answer wrongly they see the color red. In addition to this color-based feedback, players also win points as they answer questions correctly. Each round of the game has 5 questions, and at the end of each round the player can visualise his/her evolution in terms of total number of points, precision (percentage of right answers over total number of questions answered in the game), and also how far they are from reaching the next level. At the end at each level, the player can also revise all the questions of that round in order to check what he/she did right or wrong. When a user reaches a new level, there is a message which congratulates this achievement rewarding the player with a piece of a puzzle. Each level conquered unlocks a piece of the puzzle and this is explained further in the next section.

Levels: the game has 30 levels in total; though it is important to note that 28 of these are an integral part of the game and the puzzle which players unlock over time. The additional two levels (29 and 30) are not integral and are instead available for players to revisit questions they got wrong (level 29) and to continue playing the game against others, such as through duels and battles (level 30). When the player reaches the last main level (this being level 28), the algorithm reveals the full image of the puzzle. Players progress to the next level when they reach $80 \%$ of precision and answer $80 \%$ of the questions that correspond to a certain level. The difficulty degree increases level-bylevel, and topics also change as the player progresses through the game. For each level, the algorithm selects some questions randomly, including a number of questions from previous levels and some questions that the player answered incorrectly. In this way, the player has the opportunity to answer again the questions that they answered wrong in a previous attempt and learn the content again. Therefore, the user learns by trial-and-error, consolidating in this way the acquired knowledge throughout the process of playing the game.

Time pressure: for each question, users can see a clock that starts with 30 seconds and decreases over time until the player answers the question. The number of points earned in each question correspond to the time left to answer the question. The faster the player is, the higher the number of points they will receive for that question. The points systems correspond directly with the clock and therefore the maximum available is 30 points, and the minimum 0 points.
Badges: badges are a way of reinforcing user behaviors and enhancing motivation. For example, players win badges when they play in the morning (early bird badge), late at night (night owl badge), or when they perform extraordinarily (e.g. marathoner, sprinter, duel hero, or Einstein badges). The use of the badges element of the game aims to promote shortterm commitment and the fuelling of user engagement ([24]).

Power-ups: this element aims at stimulating the player with surprises and special bonuses. Power-ups occur with a probability of $50 \%$ per round. Some examples of power-ups are 'freeze-time' that allows players to freeze the clock timer described in the time pressure section, 'help' which permits a player to eliminate one of the wrong answers, increasing the probability of getting it right, and 'Super power' which allows a player to double the score obtained in a certain question. Users can choose to use the power up in any question of the round, increasing their 'freedom of choice' and enabling strategic use of power-ups throughout the game.

Duels: In order to boost users self-determination and social involvement in the game, users can challenge other users to answer a round of 5 questions. Although it is an interpersonal competition, the user has the possibility to choose with whom they want to start a duel. The challenged player also has the freedom to accept a duel or not. In duels, the player that wins gets double points whilst the player that loses receives the same number of points as they would playing a normal round.

Battles: Battles differ from duels and stimulate cooperation strategies, as they are designed to be used between teams ([13]). The game manager programs the battles in terms of duration, prize (number of points awarded to each member of the winning team), and teams involved. When a battle is scheduled, the score that each team member gets during the battle period sums up to the overall team points. In the end of the battle, the team with more points wins the battle and gets the prize.

End of game: when players finish the game and complete the puzzle, they are prevented from playing individually. However, they can still win points if they play in duels mode (as explained with level 30), challenging other players to play. The goal is twofold: first, motivate players that are at the middle of the table, as they still feel that they have a chance to win; second, to stimulate players to duel each other, promoting the development of other players. 'Alone you can go faster, but together you go further' is the 
implicit message of this gamified learning mechanism. The winners are identified on the last day of the game and the 'top 3' get a symbolic prize.

\section{Findings}

The findings here are separated into two main areas consistent with the aims of the study and research question. First, the findings explore aspects of motivation and levels of engagement, and second examine the inherent learning styles demonstrated by students. The overall findings here point towards different motivational learning modes as the main contribution of this preliminary, qualitative study.

The game 'Think Strategically' was presented to the students as a non-compulsory learning tool that they could use to complement their study for the module. This leads to a question of why students might decide to engage and play the game in the first instance. The student's motivations and learning style indicate three main modes of interaction which we call motivational learning modes, these being; (i) learners, (ii) gamers, and (iii) hybrids.

\subsection{Learners}

The mode of motivational learning we call Learners consists of students who stated that they decided to install and play the game because they wanted to learn more about Strategic Management. Players installed the game and began to use it to assess their initial level of knowledge before they started more extensive studying to revise the content after they finished their studying plan, or instead to complement their study while they are revising the module content. Learners represents those players that demonstrate higher intrinsic motivation to learn, focusing mainly on getting to the next level to unlock a fresh set of questions, so they can keep learning.

Learners were seen to often ignore the remaining gamification elements such as rankings, badges, power-ups, duels with other players, and team battles (cooperative and competitive elements). They also disliked the timed questions, which made them nervous and unable to reflect on the question content. However, on the other hand, Leaners valued elements such as repetition of wrong questions, questions with different formulations, immediate feedback, and the possibility to revise the questions at the end of each round. Learners engagement towards the game, which translated in time played, is dependent on the quantity and quality of the new questions that they unlock. For example, if they feel that the questions are repeating, and the level of difficulty is too low, they decrease their engagement towards the game and this eventually leads them to stop playing.

These players also aligned particularly closely in their learning style to sensing, in that they didn't appreciate surprises in learning and preferred more conventional techniques (answering questions, learning and topics), and also to reflective in that they prefer straightforward and introspective means of learning without demanding or distracting features. Below are example quotes from the preliminary analysis which demonstrates this:

"I played the game to learn, I don't care about the badges, I just want to play it. I know that people play games just to get the achievements, but I am not like that (...) I didn't challenge colleagues; I just wanted to play by myself."

"I normally do flash cards to memorize content, this time I didn't need to do many of those (...) Nothing changed with the game, it just replaced the flash cards process, that normally takes ages and the game saved me time, so it kind of replaced the process rather than changing it."

$\mathrm{OF}$ ( $7^{\text {th }}$ in the ranking)

\subsection{Gamers}

The mode of motivational learning we call Gamers represents quite the opposite to the mode Learners and consists of students who installed the game and used it for the elements of competition and to fulfil their competitive nature. Gamers stated that their motivation for installing and using the game was because they enjoyed the 'fun' of gaming and they enjoy the challenge of competition. Such players are also driven and engaged by rankings, points, and badges.

It was found that Gamers enjoy challenging players in the game and will wake up early or start playing after 7:00 pm to earn time-based badges. Overall, these players are the ones that most talk with colleagues about the game and spread the word, instigating team members to play to raise their team ranking position. In contrast to Learners, Gamers appreciate gamification elements such as points, levels, ranking, duels, question repetition, cooperative battles. However, Gamers might also lose their engagement towards the game even though they are clearly engaged and motivated by the overall use of games. For example, Gamers lose interest when the distance between them and the top tier players gets too 
big and competition starts to dwindle or feel out of sight. As they lose the hope to win the game, they decrease their engagement and eventually stop playing.

These players, overall, aligned closely to a number of established learning styles, particularly as intuitive learners as they prefer discovering new and exciting possibilities and relationships between concepts and excel when presented with innovative elements rather than repetition and routine learning. Further, they are active learners and prefer to learn by engaging in unique and interesting activities such as through game elements (badges, points), and by discussing and playing with colleagues or classmates. Below are example quotes from the preliminary analysis to show this mode of motivational learning:

"I told my colleagues to play and I challenged them, even after I finish the exam, I played one or two duels."

"I played the game first and after I got back to the text book to found my mistakes and corrected them, like a double review (...) I made a mistake first time, and if I made this mistake a second time I would get back to the book to find the answer, so when the question shows again I can answer it correctly."

$$
\text { HP ( } 1^{\text {st }} \text { in the ranking) }
$$

"The badges motivated me a lot. The badges changed when I used and how I used the game. I used to play later to get the badge Night Owl, for example (...) I was really trying to get the badge 'Sprinter' where you answer a round in 10 seconds, I was really trying, and this made me frustrated, but I got the Marathoner badge."

"I was a bit addicted to points as well and winning points. I used to think 'oh they have more points than me' but for how long are they playing for, this is unfair, I would like to have this information."

$\mathrm{LM}\left(5^{\text {th }}\right.$ in the ranking)

\subsection{Hybrids}

Finally, the mode of motivational learning we call Hybrids consists of the students that demonstrated elements of both learning and competition. These players enjoy the gamification mechanisms while they are learning, calling it 'funny' and 'enjoyable'. Hybrids are also the players that show higher levels of engagement towards the game regarding time played. While the learning objective (intrinsic motivation) keeps them focused on the long-term goal of learning, the key game elements such as badges, levels, powerups, rankings keep their levels of engagement high throughout the game, and they keep playing for longer periods overall.

In relation to learning styles, hybrids are more difficult to position due to their mixed and divisive nature in learning. However, they align particularly closely to visual and verbal learning in that they seemingly thrive through a mixture of visual information transmission methods such as when being awarded badges, seeing leader boards, and unlocking new levels, while in relation to verbal they still relish the opportunity to engage with written explanations and working through questions. Again, example quotes from the preliminary analysis demonstrates this mode below:

"I played the game to revise the content of the course, because you can answer the questions and you know if it is right or not immediately."

"I felt very motivated with the prize, thanks for the chocolates! (...) I always need to be motivated, it does not matter what the motivation is, even a 'thanks' is fine for me (...) On the bag that you gave to me, where you wrote 'first', I wrote the date, the name of the module, and your name (the module leaders name) and I stapled in the bag and I will keep it."

"I used to stop the game during the day to play at 7:00 pm just to get the badge Night Owl."

SK $\left(4^{\text {th }}\right.$ in the ranking, but the $1^{\text {st }}$ to finish the game)

\section{Discussion and conclusion}

Our findings indicate that, ultimately, the players that succeeded most in the game were the ones who combined elements of intrinsic and extrinsic motivation, and also a range of different learning styles. While the learning objective (intrinsic motivation) kept them focused on the long-term goal of learning, the game elements such as badges, levels, power-ups, and rankings also ensured engagement levels were kept high throughout the game.

In contrast, players that presented higher either extrinsic or intrinsic motivation had lower levels of engagement overall with the game. This result partially aligns and challenges Nicholson's ([24]) argument about reward-based gamification. Nicholson argues that reward-based gamification can be useful in 
the short-term. However, it can be harmful to intrinsic motivation in the long run. The preliminary results of this paper tempt us to defend that reward-based gamification elements have different impact on different groups of educational gamification players. While reward-based gamification elements decrease the motivation of Learners, for which gamification elements are just a distractor; for Gamers, rewardbased gamification constitutes their main motivation. Finally, in the case of Hybrids, the reward-based gamification works as an enhancer for the intrinsic motivation.

Our research offers implications in its aim to study the coaction between of motivation and learning styles, and how users motivated by games begin to demonstrate certain learning styles more prominently than others. By approaching this through a qualitative research design, we move away from quantitative means of testing motivation and learning styles and instead turn to qualitative design to examine through rich opinion of users how they used the game and begin to interpret the emerging dynamic of motivation and learning style.

Our future research research shall investigate further the use of the 'Think Strategically' game, expanding its use to more players and at different levels of study. There is also potential to expand the use of the ILS framework, which is used to interpret the early findings in this preliminary study but has potenital to be used more extensively when interpreting rich qualitative data (again we call for more qualitative research of this nature in expanding the scope of gamification research generally) or like other studies use this to test learning styles through more quantitative modes of inquiry, and then make further unique contributions through combining this with other distinct lens' of motivation. It is also our intention to further conceptualize our findings, drawing a matrix or framework which will be of value to researchers and also to professionals such as game designers to consider in their own practice.

In sum, our preliminary study has yielded insights about the use of the game, and contributes through the qualitative design of this study a rich interpretation of motivation and learning styles and their coaction in educational gamification.

\section{References}

[1] Abt, C.C. "Serious Games". Viking, New York. (1970).
[2] Buckley, P, and Doyle, E. "Gamification and student motivation." Interactive Learning Environments 24.6 (2016): 1162-1175.

[3] Buckley, P, and Doyle, E. "Individualising gamification: An investigation of the impact of learning styles and personality traits on the efficacy of gamification using a prediction market." Computers \& Education 106 (2017): 4355.

[4] Coffield, F, Moseley, D, Hall, E, and Ecclestone, K. "Learning styles and pedagogy in post-16 learning: A systematic and critical review." (2004).

[5] Deci, E.L, and Ryan, R.M. "The empirical exploration of intrinsic motivational process". In L. Berkowitz (Ed.), Advances in experimental social psychology. New York: Academic Press. (1980).

[6] Deci, E.L. "Intrinsic motivation". New York: Plenum. (1975).

[7] Deterding, S, Dixon, D, Khaled, R, and Nacke, L. "From Game Design Elements to Gamefulness: Defining 'Gamification'”, 2011.

[8] Eisenhardt, K. M. "Building Theories from Case Study Research." Academy of Management Review 14:4 (1989): 532-50.

[9] Felder, R.M, and Silverman, L.K. "Learning and teaching styles in engineering education." Engineering education 78.7 (1988): 674-681.

[10] Felder, R.M, and Spurlin, J. "Applications, reliability and validity of the index of learning styles." International Journal of Engineering Education 21:1 (2005): 103-112.

[11] Hamari, J, Koivisto, J, and Sarsa, H. "Does gamification work?--a literature review of empirical studies on gamification." System Sciences (HICSS), 2014 47th Hawaii International Conference on. IEEE, (2014).

[12] Hartley, S.E. "The chemical composition of plant galls: are levels of nutrients and secondary compounds controlled by the gall-former?" Oecologia 113.4 (1998): 492-501.

[13] Johnson, D. W, Maruyama, G, Johnson, R, Nelson, D., and Skon, L. "Effects of cooperative, competitive, and individualistic goal structures on achievement: A metaanalysis". Psychological Bulletin, 89:1 (1981): 47-62.

[14] Kapp, K. M. "The gamification of learning and instruction: Game-based methods and strategies for training and education". San Francisco, CA: John Wiley \& Sons. (2012).

[15] Kolb, D. A. "Learning Style Inventory, Revised Edition”. Boston, MA: Hay Group, Hay Resources Direct. (1985).

[16] Leonardi, P.M, and Rodríguez-Lluesma, C. "Sociomateriality as a Lens for Design: Imbrication and the constitution of technology and organization." Scandinavian Journal of Information Systems 24:2 (2012): 4.

[17] Liu, D, Santhanam R, and Webster, J. "Toward meaningful engagement: a framework for design and 
research of gamified information system.” MIS Quarterly 41:4 (2017): 1011-1034.

[18] Loftus, G.R, and Loftus, E.F. "Mind at play; The psychology of video games". Basic Books, Inc. (1983).

[19] Lepper, M.R, and Malone, T.W. "Intrinsic motivation and instructional effectiveness in computer-based education." Aptitude, learning, and instruction 3 (1987): 255-286.

[20] Malone, T.W. "What makes things fun to learn? Heuristics for designing instructional computer games." Proceedings of the 3rd ACM SIGSMALL symposium and the first SIGPC symposium on Small systems. ACM. (1980).

[21] Martí Parreño, J, Sanz-Blas, S, Ruiz-Mafe, C, and Aldas-Manzano, J. "Key factors of teenagers' mobile advertising acceptance." Industrial Management \& Data Systems 113:5 (2013): 732-749.

[22] Miles, M., and Huberman, A. Qualitative Dada Analysis. Sage Publications. (1994).

[23] Feldman, J, Monteserin, A, and Amandi, A. "Can digital games help us identify our skills to manage abstractions?" Applied Intelligence 45:4 (2016): 1103-1118.

[24] Nicholson, S. (2014). "A recipe for meaningful gamification". Gamification education in business, 1-20.

[25] Piaget, J. "Introduction à l'épistémologie génétique. T. I: La pensée mathématique." (1952).

[26] Poropat, A. E. "A meta-analysis of the five-factor model of personality and academic performance." Psychological bulletin 135:2 (2009): 322 .

[27] Reeves, B. and Read, J.L. "Total Engagement: Using Games and Virtual Worlds to Change the Way People Work and Businesses Compete". Harvard Business School Press, Boston, MA. (2009).

[28] Strauss, A., and Corbin, J. "Basics of Qualitative Research: Grounded Theory Procedures and Techniques. Newbury Park, CA: Sage. (1990). 